\title{
A DISTINÇÃO ENTRE REPRESENTAÇÃO DE PALAVRA E REPRESENTAÇÃO DE COISA NA OBRA FREUDIANA: MUDANÇAS TEÓRICAS E DESDOBRAMENTOS FILOSÓFICOS
}

Magdalena Arnao

\author{
Licenciada em \\ Filosofía pela \\ Universidad Nacional \\ de Córdoba (UNC); \\ doutoranda em \\ Filosofia pelas \\ Facultad de Filosofía \\ y Humanidades \\ (UNC); bolsista pelo \\ Consejo Nacional \\ de Investigación en \\ Ciencia y Técnica \\ (Conicet); membro \\ da equipe de pesquisa \\ do Centro de \\ Investigaciones de la \\ Facultad de Filosofía \\ y Humanidades \\ (Ciffyh/UNC); \\ adstrita em "Filosofía \\ de las Ciencias" \\ e "Seminario \\ metodológico" \\ (FFyH/UNC); \\ colaboradora Docente \\ da Faculdade de \\ Psicologia (UNC). \\ Tradução: Pedro \\ Henrique Bernardes \\ Rondon
}

RESUMO: A distinção representação coisa/palavra foi empregada por Freud em 1891, e ele a reintroduz nos seus trabalhos sobre metapsicologia. A relação entre essas duas representações sintetizou, em 1915, uma ruptura tanto com a psicologia da época, como com uma prolongada tradição filosófica. Esse rompimento problematiza muitos dos supostos mais firmemente enraizados até hoje na filosofia. Procura-se aqui investigar o significado da divisão representação palavra/coisa, tanto para a psicanálise, como para a filosofia representacional, e assinalar alguns dos efeitos mais importantes da mesma.

Palavras-chave: Representação palavra, representação coisa, filosofia, realidade psíquica, representação.

ABSTRACT: The distinction word representation/thing representation in Freud: Theoretical changes and philosophical consequences. Freud reintroduces the distinction thing representation/word representation in metapsychological works after it was used in 1891. This representational pair synthesizes, in 1915, a break both with the psychology of the time and with a long philosophical tradition. Such break turns problematic many of the suppositions deeply rooted in today's philosophy. This article inquires about the significance of the division word/thing representation for psychoanalysis as well as for the representational philosophy, and it points out some of the most important effects of it.

Keywords: Word/thing representation, psychological reality, philosophy, representation. 


\section{I}

A distinção entre representação de palavra e representação de coisa aparece pela primeira vez na produção de Freud em 1891, quando ainda não havia as condições para o surgimento da psicanálise, e foi reintroduzida em 1915 na metapsicologia, obra de sistematização psicanalítica, na qual a mencionada distinção representa papel axial. Na ocasião em que Freud volta a trazer o problema da representação nos termos em que o propusera numa fase tão inicial de sua produção, o par palavra/coisa foi plenamente ressignificado, de tal maneira que nele encontramos expressados muitos dos pressupostos fundamentais da teoria psicanalítica, pressupostos que marcam uma ruptura não apenas em relação a outras concepções psicológicas, mas em relação a muitos dos pressupostos mais fortemente arraigados no pensamento filosófico.

Proponho-me, aqui, a examinar este par conceitual tal como foi utilizado por Freud nos seus trabalhos da metapsicologia, a fim de estabelecer os pressupostos sobre os quais se estabelece, e o alcance do mesmo como expressão da quebra conceitual instaurada pela psicanálise em relação à tradição da pesquisa em psicologia e no território de alguns problemas filosóficos cruciais.

Em primeiro lugar, vou indagar a propósito da noção de representação filosófica, indicando o marco conceitual filosófico no qual a noção de representação tem sido enquadrada pelo menos desde a modernidade, e sua herança nos primeiros momentos de consolidação da psicologia. Na seção II, vou me concentrar na teoria freudiana inicial da representação, esclarecendo as ligações entre o par representação-afeto e a significação da distinção entre representação de palavra e representação de coisa, a fim de mostrar a dependência da noção de representação, nesse período, quanto à tradição filosófica mencionada antes. Na seção III, vou analisar o complexo jogo de relações que a relação palavra/coisa pressupõe na metapsicologia, para em seguida apontar as suas implicações. Na seção IV, vou estabelecer uma comparação com o trabalho de 1891 e as mudanças nas implicações filosóficas que sua reintrodução na metapsicologia significa. Por último, na seção V, vou concluir com o impacto que uma concepção do jogo representacional significa, em particular para discussões filosóficas que continuam vivas — como o é a relação pensamento/linguagem — que em geral descuidam intencionalmente das contribuições que a visão psicanalítica possa oferecer.

\section{II}

A noção de representação teve relevância central em diferentes momentos da história da filosofia e através de problemas de diferentes naturezas. A noção de representação tem sido empregada, em termos gerais, para designar a forma sob a qual algo se apresenta, como distinta da simples apresentação de alguma coisa; enquanto tinha a ver com uma atitude cognoscitiva, a dita noção se referia à 
maneira segundo a qual um sujeito, ou um meio de representação, capta algo que se lhe apresenta.

Assim, o termo 'representação' se refere ao modo de apreensão de um objeto ou fenômeno por parte de um sujeito (ou meio de representação, como o caso de um livro, de uma pintura, etc.), o que significa que para que haja um ato de representação é preciso que haja alguém (ou algo) que representa alguma coisa (não necessariamente algo distinto de si mesmo; no caso do sujeito, é possível falar deste como representando a si mesmo). Dessa maneira, a filosofia moderna concentrou seu interesse na noção de representação, uma vez que é um problema central para a filosofia moderna a relação cognoscitiva do sujeito e do mundo e, portanto, o alcance e as formas de representação, de tal forma que nos vemos com pelo menos três componentes para desenredar: o ato de representar (as capacidades cognitivas do sujeito cognoscente), o representado (que suscita o problema do alcance do conhecimento e tem implicações realistas, idealistas, céticas, dependendo do grau de confiança no dito acesso), e a representação como resultado da dita ação sobre o objeto. ${ }^{1}$

É por isso que os empregos da noção de representação que mais importaram para a filosofia, desde a modernidade, têm sido aqueles de viés cognoscitivo, visto que as preocupações nas quais estavam imersos vários dos distintos usos de representação eram de natureza epistemológica. ${ }^{2}$

Para a modernidade, a separação entre o sujeito que percebe, que tem experiência de um mundo que está fora de seu entendimento, e o mundo como algo objetivo, independente de quem o apreende, é uma separação que, embora indubitável, é problemática. A moderna filosofia do conhecimento andou em torno da tentativa de determinar onde um e outro começavam e terminavam. Enquanto o problemático era o acesso à realidade, o que não estava em dúvida era que o referido conhecimento, para ser conhecimento, tinha que ser objetivo, sendo que o objetivo é relativo ao mundo e nunca pode conter elementos do sujeito cognoscente. Dentro desse enquadre, a realidade é sempre realidade externa, a representação que a filosofia considera valiosa é a representação cognoscitiva e, por conseguinte, é uma representação que apreende de algum modo o mundo externo ao sujeito; é em virtude de sua capacidade para captar a realidade que as representações cognoscitivas têm importância para a filosofia.

\footnotetext{
${ }^{1}$ Atualmente a noção de representação voltou a ocupar lugar importante na filosofia, em especial na filosofia da ciência, indagando o status que cabe atribuir a tal noção a partir das críticas à epistemologia clássica de meados do século XX, crítica presente a partir de diversas linhas filosóficas como a vertente proveniente do pragmatismo filosófico (RORTY, 1989; PUTNAM, 1988) e da filosofia continental (ver TAYLOR, 1997). Para um quadro geral do problema da representação na epistemologia atual, ver Ibarra \& Mormann (2005).

${ }^{2}$ A ressalva é válida uma vez que a noção de representação também estava muito presente nas discussões teológicas e estéticas.
} 
Este modelo de conhecimento e de sujeito cognoscente, ligado à separação entre sujeito/objeto, sendo a realidade concebida unicamente como aquilo que é externo ao sujeito, e o objeto como algo que é dado, será questionado mais tarde. Esta ruptura com os mencionados pressupostos, que dentro da epistemologia se fará esperar até meados do século XX, em muitos sentidos é dada pela irrupção da psicanálise no campo do saber, mesmo quando, pelo lado de Freud, a maneira de conceber a produção científica seja conservadora. Os pressupostos que vamos analisar aqui rompem muitas das intuições centrais que a filosofia moderna cunhou a propósito das noções de realidade, sujeito cognoscente e representação.

Como já apontei antes, a noção de representação mergulha suas raízes no contexto do problema do conhecimento moderno. Entretanto, outro fato é relevante neste período, e terá extrema importância para o nascimento da psicologia: o problema do conhecimento, que tinha ocupado a atividade filosófica desde seus primórdios, se desloca aqui de uma pergunta pela natureza para uma pergunta pelo próprio sujeito que conhece, se internaliza no sujeito e nas operações do entendimento. Este fato se evidencia com a centralidade que adquiriram na filosofia moderna o problema da mente e a descrição de suas faculdades como parte do problema de compreender as fontes do conhecimento e outorgar às ciências um método baseado na validade. Encontramos na modernidade os antecedentes filosóficos daquilo que mais tarde veio a se consolidar como disciplina psicológica, bem como suas discussões acerca das operações que o entendimento leva a cabo para obter o dito conhecimento.

Como parte dessa separação mente-mundo, podemos reconhecer outro pressuposto intimamente ligado implicado na idéia de que as representações da mente se referem a e, por conseqüência, adquirem seu conteúdo a partir da realidade que representam. Seu conteúdo é, portanto, referencial. Neste contexto, a filosofia privilegiou a noção de representação como um tipo de relação especular e, portanto, referencial.

O peso deste último pressuposto para a história da psicologia e para a valorização do alcance filosófico que a dita história sustenta, só é vislumbrado com a irrupção que o aparecimento da psicanálise representa para o desenvolvimento da psicologia. A forma de conceber os fenômenos mentais, e a vida mental como um todo, por parte da teoria psicanalítica apresenta novos pressupostos com base nos quais é possível compreender a vida anímica. A noção de representação que a teoria psicanalítica vai utilizar é um exemplo disso. A noção de representação, muito complexa, introduzida por Freud com a psicanálise, envolve o abandono de pressupostos filosóficos herdados pela psicologia experimental da época e por sua psicologia mais inicial. É a partir da tentativa de compreender os novos pressupostos que a mencionada noção oferece, que podemos dimensionar as 
distâncias que vão ser instauradas para sempre entre modos diametralmente diferentes de conceber a mente humana, a vida anímica.

Portanto, apesar das longas disputas em torno da conformação da psicologia científica, vai ficar notório, com o desenvolvimento da psicanálise, que cada uma das tentativas de oferecer uma teoria científica dos fenômenos mentais adota dois pressupostos metafísicos como base comum: por um lado, que qualquer que seja a forma adotada pelas representações (seja como idéias, sensações, pensamentos) e qualquer que seja o tipo de relação que se estabeleça entre elas, seu conteúdo é explicado referencialmente, isto é, o conteúdo das representações mentais é dado por sua referência àquilo a que se refere à representação que está em seu lugar, mesmo quando possa não ser real. ${ }^{3}$ Isto implicava certa univocidade do representado ou do conteúdo das representações, por um lado, conjugado a uma forte tendência a considerar que o conteúdo das representações, acerca das quais versam as nossas crenças, remete a algo externo ao sujeito que representa estando no mundo, sendo um acontecimento no mundo; por outro lado, e talvez como pressuposto mais fundamental do que o anterior, a separação ontológica entre sujeito e objeto. São pressupostos herdados das distintas correntes filosóficas que as precederam.

Com efeito, Freud vai de início aderir a esta visão de mundo, segundo a qual o conteúdo das representações depende do mundo externo à mente que apreende os ditos conteúdos, para logo tomar distância, gerando uma teoria ${ }^{4}$ das representações cujos conteúdos não dependem de uma referencialidade à maneira de uma causalidade externa à realidade psíquica, nem da relação cognoscitiva da mente com o mundo. Assim podemos diferenciar dois momentos no pensamento de Freud, por meio da mudança que sua noção de representação indica, num e noutro caso, e dos pressupostos que sustentam a citada mudança. É nesta mudança de concepção que podemos apreender sua ruptura e, portanto, a originalidade de sua teoria do mental, e que enfim virá permitir que nos questionemos a propósito da continuidade de sua etapa pré-analítica com os pressupostos centrais adotados pela psicologia alemã da época, e pela psicologia experimental que estava nascendo.

Para poder captar essa diferença, deveremos, portanto, nos concentrar minuciosamente no percurso que a noção de representação descreveu desde seus primeiros aparecimentos nos trabalhos escritos de Freud, até a metapsicologia.

\footnotetext{
${ }^{3}$ Estou pensando aqui em Brentano e seu traço distintivo do mental, a intencionalidade, que contemplava a possibilidade de os estados mentais serem acerca de algo (coisas, estados de coisas ou fenômenos) inexistente, o que chamou de 'inexistência dos objetos intencionais'.

${ }^{4}$ Estou falando aqui de teoria para dar a entender que o que Freud faz é mais complexo do que dar uma simples noção de representação, ainda quando o termo 'teoria' possa ser excessivo uma vez que Freud não segue até o fim algo tão compacto e sistematizado como uma teoria das representações.
} 


\section{III}

Se o termo 'representação' aparece como um conceito central desde muito cedo na obra de Freud, é preciso buscar as razões disso na psicologia alemã dos fins do século XIX, fundamentalmente na figura de Herbart, o qual impulsionara a idéia de que as representações são o conceito mais básico do psiquismo, e a distinção entre representação e afeto. A herança herbartiana em Freud tem sido muito discutida, e é opinião de alguns que ela se estende até algumas das intuições mais básicas da metapsicologia (cf. ASSOUN, 1981; BERCHERIE, 1983). Por volta de $1895-96,{ }^{5}$ na mesma linha de Herbart, Freud contrapõe a representação ao afeto, sendo possíveis sua separação e um destino diferente. Dessa maneira, a divisão representação-afeto está na base da explicação dos primeiros modelos teóricos das psiconeuroses que Freud propõe, e onde localizamos aquilo que com freqüência se tem chamado de teoria do trauma. Com efeito, o que explica a divisão é o fato traumático, e o que a catarse busca como objetivo do tratamento é a união da representação ao afeto correspondente.

Recordemos que este par está em função de uma explicação etiológica, à medida que uma vivência hostil é considerada como desencadeante de uma reação traumática. Para que seja considerada hostil, uma vivência deve ter dado lugar a sentimentos de pavor e, além disso, ter sido inesperada (cf. MINHOT, 2003). Por outro lado, o afeto que acompanha a representação é sufocado. Para deixar de estar sufocado, o afeto, tendo encontrado outro caminho, precisa voltar àquilo que lhe deu origem, voltar à representação da qual se desprendera originalmente.

De alguma forma trata-se de levar o afeto descarrilado à recordação da vivência real. Apenas tornando consciente o vínculo entre vivência e afeto é que é possível a cura. A excitação provocada pelo afeto precisa ser descarregada, e para isso torna-se fundamental a recordação do afeto. É preciso voltar a conectá-lo à realidade (como representação).

As representações traumáticas adquirem significado com relação à recordação do fato traumático efetivo, externo e historicamente anterior e, por outro lado, a um fator econômico, uma vez que as conseqüências do trauma são vistas na incapacidade do aparelho psíquico para descarregar as excitações de acordo com o princípio da constância. Neste esquema, que um fato seja considerado como traumático pelo psiquismo, depende de determinadas circunstâncias que impedem uma reação adequada à situação, entre as quais encontramos a situação psicológica do sujeito passivo, o conflito psíquico que impede a integração da

\footnotetext{
${ }^{5}$ É difícil situar um momento inaugural em que Freud abandona a investigação primeiro fisiológica e microanatômica com Brücke e logo neuropatológica com Meynert para dedicarse em plenitude à investigação psicológica, porém aqui vamos nos concentrar nos escritos pré-analíticos, em especial no trabalho sobre as afasias, de 1891, e no "Projeto para uma psicologia científica”, de 1895.
} 
vivência de modo consciente (defesa) e, o que é relevante aqui, da situação efetiva. Nessa direção, Freud continua na linha de pensamento que localiza as representações não apenas como a matéria básica dos fenômenos psíquicos, mas também como resultando de causas externas; assim, em algum sentido, o conteúdo das representações é exterior ao aparelho anímico.

Se retomarmos a pergunta a propósito de como as representações adquirem seu conteúdo, vamos encontrar a resposta nesse primeiro momento na realidade efetiva, no mundo externo. As representações adquirem seu conteúdo por uma relação causal com o entorno. Na mesma linha, Minhot afirma que

“A causa eficiente da doença provém, então, dessa realidade material. Embora seja uma representação, a causa para a qual o método catártico se dirige é uma que tem como referente uma coisa no mundo: é a realidade material determinando a realidade psíquica." (MINHOT, 2003, p.107).

Conforme anunciei, além da tese sobre a separação representação-afeto, Freud faz alusão a outra divisão que envolve as representações. Na carta 52 (1896/1998), Freud esboça um esquema de transcrições e localiza no pré-consciente as representações de palavra. A propósito destas, numa nota de rodapé ele nos remete a seu trabalho de 1891 sobre as afasias. A idéia de representação que introduziu ali se encontra enquadrada numa lógica associacionista, em que as representações são explicadas por meio de impressões ou conjunto de impressões, como um aglomerado de dados adquiridos sensorialmente e organizados por cadeias associativas.

Por sua vez, distingue entre representações de objeto e representações de palavra. Cada uma dessas representações “é um complexo associativo das mais diversas representações visuais, táteis, cinestésicas e outras” (FREUD, 1891/2000, p.211). Para definir a ontologia das representações de objeto, Freud se vale da filosofia de John Stuart Mill que afirma que as ditas representações, ainda quando pareçam uma "coisa” acabada, mantêm com o objeto do mundo uma relação de aparência e, portanto, incompleta. A isso ele acrescenta que "a representação de objeto nos aparece como algo não fechado e que dificilmente poderia sê-lo, enquanto a representação de palavra nos aparece como algo fechado, embora suscetível de ampliação" (idem, p.212).

A divisão 'representação de palavra-representação de objeto' explica como se enlaça a palavra com o mundo, como a palavra enquadra a realidade, nessa operação de nomeação. Nesse sentido as representações de objeto são sempre abertas em comparação à representação de palavra, que é fechada. A afirmação de Assoun segundo a qual Freud situa os objetos do mundo do lado da coisa em si e se posiciona, neste ponto, do lado de uma teoria kantiana do conheci- 
mento, é pertinente por duas razões: 1) porque insiste na relevância do caráter da representação de objeto como algo que, ao pertencer à ordem do mundo, se encontra inatingível em última instância e, dessa maneira, localiza o Freud das afasias dentro de uma tradição que dá continuidade ao modo de problematizar e conceber os funcionamentos básicos do aparelho mental nos mesmos termos em que tinha sido proposta na filosofia da psicologia derivada da concepção do conhecimento discutida aqui na seção I, e 2) porque a introdução da tonalidade kantiana das representações de objeto em 1891 contrastará com o modo de referência que o próprio Freud faz ao filósofo alemão na reintrodução do par palavra/coisa em 1915 para falar da realidade psíquica, já não em relação de dependência e submissão à realidade exterior, mas sim como referida a um em si psíquico.

Como se conjugam essas duas teses a propósito das representações no período pré-analítico? Por um lado, a divisão entre representação e afeto dá conta da dinâmica das representações e de seu papel na etiologia das neuroses. Por outro, a divisão representação de palavra-objeto, dá conta da relação das representações com o mundo (por meio da palavra); dá conta, em última instância, de que há uma relação com o mundo, uma relação que, numa cadeia associativa, vai do mundo às representações de objeto, e destas às representações de palavra. Seu realismo está situado, neste período, pelo lado de um realismo em relação ao mundo exterior, isto é, que o conteúdo das representações se refere, em última instância, a sua referência ao mundo.

Por isso, podemos afirmar que Freud tem em mente, neste período de sua produção, uma relação realista do psiquismo com o mundo. Na teoria do trauma se vêem com clareza as conseqüências dessa visão para a etiologia das neuroses: são as recordações de fatos concretos, estabelecidas com o tempo, que explicam causalmente os sintomas.

Pelo que temos visto até este momento, este período da obra de Freud não acrescenta nada em relação àquilo que a tradição filosófica e psicológica tinha desenvolvido em torno das representações. Não introduz novidade alguma, uma vez que toma como pressuposto básico a relação referencial das representações quanto ao mundo exterior.

No entanto, com a psicanálise Freud instaura uma novidade radical na forma de considerar as representações. A novidade residirá numa forma de propor o problema das representações que permite, por um lado, sair da dependência à causalidade externa das mesmas, e por outro, à separação sujeito-objeto nos termos propostos pela tradição filosófica. Visto desta maneira, Freud não apenas inova no campo da psicologia, mas a possibilidade de estabelecer uma distância aos pressupostos fundamentais da psicologia da época também vem trazida pela capacidade de separar-se dos pressupostos filosóficos que a acompanham. 


\section{IV}

Até aqui apontei que, no momento pré-analítico analisado, Freud se coloca na linha de pensamento da psicologia psicofísica do século XIX. Com o modelo da primeira tópica, o Pai da Psicanálise se afasta desta exigência para oferecer uma explicação psicológica dos fenômenos mentais. A passagem para a estruturação da primeira tópica significa uma série de abandonos e de novas aquisições. Ao entrar de fato no terreno das explicações psicológicas, Freud renuncia às explicações em termos neurológicos, isto é, renuncia à explicação por meio de magnitudes de excitação neurológica para falar de processos de descarga de energia psíquica, e ao mesmo tempo introduz a idéia de uma localização psíquica que não é análoga a uma localização anatômica.

Como Minhot aponta, "A implicação metafísica fundamental desta inovação reside na possibilidade que este novo conceito de inconsciente oferece para conceber uma realidade psicológica irredutível à realidade empírica” (2003, p. 95). Ao separar os sistemas, Freud torna mais complexa a idéia do conteúdo mental das representações. Vejamos de que maneira.

Em 1915, nos artigos metapsicológicos, Freud utiliza a noção de representação de dois modos diversos: como representantes (Repräsentanten) e como representação (Vorstellung). Isso é assim uma vez que as representações são compreendidas a partir da problemática noção de pulsão. Nesse sentido, o afastamento de Freud em relação à psicologia científica de sua época está muito marcado pelo momento inaugural em que as representações deixam de ser a pedra angular dos fenômenos psíquicos para dar lugar às pulsões, ou para ser subsidiárias destas. Embora as representações continuem exercendo um papel importante na teoria psicanalítica, sua significação estará indissoluvelmente ligada ao conceito de pulsão e ao pressuposto do inconsciente, compreendido já não como um limiar da consciência como em Herbart, mas sim como um sistema cujos conteúdos constituem “o propriamente psíquico” (cf. FREUD, 1915/2000).

Por um lado as pulsões são compreendidas como uma forma de representação de um estímulo endógeno, Freud as chama de representantes [Repräsentanten] psíquicos dos ditos estímulos, e o são em sentido substitutivo, não especular nem mimético do termo, isso em virtude de que as próprias pulsões não são representações.

Por sua vez, as pulsões estão representadas no Ics por representações (no sentido de Vorstellungen). Essas representações que são agentes representantes de pulsão tampouco estão numa relação isomórfica a propósito da pulsão (são Repräsentanten).

Nos dois casos esses representantes não representam de maneira isomórfica ou especular. A pulsão não é igual ao estímulo endógeno, nem é uma tradução do mesmo, uma vez que ao instaurar o âmbito do psíquico, não compartilha 
nem as propriedades nem as leis do estímulo. Do mesmo modo, os agentes representantes de pulsão, as representações de coisa das quais Freud vai falar, representam a pulsão, porém não por se referirem a esta ou colhendo suas propriedades ou suas características. Estas representações de coisa — conteúdo do inconsciente — são regidas pelos mecanismos específicos do processo primário (condensação e deslocamento) em virtude do qual seu significado é dado por um jogo de relações com outras representações e grandezas de energia psíquica; não representam de modo unívoco.

Fica claro que pulsão não é uma representação (não é Vorstellung) mesmo quando seja representante psíquico de uma excitação endógena. Representa uma energia endógena, não por meio de uma tradução que a torna representação daquilo que representa, mas sim pela força psíquica que a dita excitação acarreta. Representa sendo força, impulso, tendência. Na condição de força, é/se faz presente por si mesma, e não por referência a outra coisa. Por sua vez, na mesma linha, os agentes representantes de pulsão (representações de coisa) embora sejam representações (são Vorstellungen), não representam de modo isomórfico uma pulsão ou uma multiplicidade delas, estas não são seu referencial.

Por sua vez, as representações de coisa (esses agentes representantes de pulsão) na condição de Vorstellungen, na condição de representações, têm um conteúdo. Uma representação, conforme propusemos no início, é acerca da alguma coisa, tem caráter intencional. No caso das representações de coisa, seu conteúdo é colhido ou vislumbrado, em certo sentido, pelas representações de palavra. Freud reintroduz a distinção representação de palavra/representação de coisa em "O inconsciente" (idem) para dar conta da problemática relação entre representações inconscientes e representações conscientes. Estas representações de coisa constituem o conteúdo do inconsciente; na condição de Vorstellungen seu conteúdo é representacional. Freud introduz uma variação significativa a propósito do trabalho de 1891. A representação de objetos da qual se ocupara no trabalho sobre as afasias era uma representação de objetos externos, pertencentes à realidade material. Estando preocupado agora com a realidade psíquica, os termos reintroduzidos adquirem outra aplicação; assim, indica que "aquilo que ali tínhamos denominado representação de objeto [Objektvorstellung] consciente agora se decompõe para nós na representação de palavra [Wortvorstellung] e na representação de coisa [Sachvorstellung]” (idem, p.197).

Nem as representações de coisa, conteúdo do inconsciente, nem sequer as representações de objeto, amálgama de representações de coisa (inconscientes) e representações de palavra, remetem ao mundo da realidade material, posto que estão tentando dar conta de uma realidade psíquica, e daquilo que constitui um objeto psíquico. O esquema é mais complexo, uma vez que fica claro que essas representações de coisa não são as coisas do mundo externo, da realidade objetiva, 
mas ao mesmo tempo consistem no "investimento, se não da imagem mnêmica direta da coisa, pelo menos de traços mnêmicos mais afastados, derivados dela” (idem, p.198). Esses traços mnêmicos, essas representações, é que constituem os agentes representantes da pulsão, uma vez que são representações às quais a libido se prende. Isto quer dizer que, em certo sentido, as representações de coisa provêm de, ou remetem a, representações sensoriais, porém o conteúdo das mesmas não é determinado pela coisa representada. A representação aqui se distingue do traço mnêmico, uma vez que a primeira reinveste, reaviva, este traço, que em si mesmo não é mais do que a impressão de um acontecimento.

Por sua vez, temos notícia da representação de coisa por sua ligação com a representação de palavra, mas o conteúdo que se transmite à palavra não é o do referencial da representação de coisa, de um referencial externo (objeto), mas sim aquele que resulta do jogo dessa representação com outras representações de coisa, uma vez que estas são regidas pelo trabalho primário, sendo dessa relação que surge seu sentido, seu significado, e é isso que é colhido pela representação de palavra.

A conseqüência disso é que as representações de palavra não significam uma representação de coisa, não se relacionam como signo e referencial; nesse sentido, Minhot aponta que

\begin{abstract}
"Aqui tampouco temos uma relação referencial, as representações de coisa não são referentes das representações de palavra com as quais se ligou. A representação de palavra não se liga com representação de coisa a partir de todos os seus componentes, mas sim somente a partir da imagem sonora. Não podemos interpretar essa ligação como semântica; uma representação de palavra não denota uma representação de coisa, mas sim a primeira é uma tradução da segunda, já que se trata de duas linguagens que constituem suas próprias representações.” (MINHOT, 2003, p.113-14)
\end{abstract}

Nesse sentido, a representação de palavra traduz uma trama de representações inconscientes. Devemos, porém, entender que aqui tradução pressupõe duas linguagens diferenciadas e, portanto, um resto, uma perda, um sentido que escapa. Uma tradução aqui é uma tentativa de captar algo que, por sua natureza, sempre escapa.

Por isso, essa representação que se traduz em representação de palavra não remete a uma única representação; remete, como dissemos, a uma associação de representações. Nesse sentido, o que pode ser levado à palavra (pré-consciente) é um aspecto dessa trama de representações, o qual se liga a algumas palavras, o fio da meada. Essas representações de coisa sofreram as ações do processo primário, por um complexo jogo com outras representações de coisa, de tal maneira que aquilo que aparece ligado à representação de palavra está desfigurado, como as imagens do sonho, por esses processos. 
Esse sentido está oculto, disfarçado pela representação de palavra; deve, portanto, ser desvelado, retraduzido. "Por isso é possível a interpretação que, como uma exegese, não busca algo externo àquilo que se interpreta. Todo o sentido está contido no signo, no texto” (p.114). Podemos entrever em que sentido as ora denominadas representações de objeto são representações de coisa mais representações de palavra, isto é, são representações conscientes: enquanto as representações de coisa se referem ao mundo interno, à “coisa interna”, as representações de objeto tentam referir-se àquilo que se torna objeto para a consciência; não esqueçamos que a representação de objeto aqui é representação de palavra mais representação de coisa, isto é, um devir consciente, um presentificar como objeto de consciência um resto daquilo que é pura coisa, um em si que só pode ser apreendido por representações de palavras que, sendo de outra ordem, não têm como assegurar sua tradução fiel. Nesse sentido, o par palavra/coisa e ainda aquilo que aqui, na metapsicologia de 1915, Freud chama de 'representação de objeto’, são termos que dão conta do âmbito de representação, transformação e devir dos processos psíquicos.

Desse modo, a interpretação de Assoun induz a confusão, uma vez que fala do objeto da representação objetal metapsicológica como se com esta Freud estivesse se referindo àquilo que é externo ao psiquismo. Assim, ele diz que "o termo Objekt evidencia o pólo objetivo, correlato da idéia e da palavra; o termo Sache enfatiza a 'coisidade' do processo representacional” (ASSOUN, 1993, p.105). Dito nesses termos, pareceria que a representação de objeto (Objektvorstellung) dá conta da relação do psiquismo com o mundo externo, como correlato do sujeito com algo externo a ele e compartilhado com outros em igualdade de percepção, no sentido daquilo que corresponde à ordem do que é o objetivo, o que é comum, independentemente de para quem, enquanto a representação de coisa indicaria um objeto interno, uma apercepção interna. Entretanto, o Objektvorstellung metapsicológico designa não uma saída do psiquismo, mas exatamente o inverso, o resultado do acesso à consciência de alguns vestígios do conteúdo inconsciente, daquilo que este guarda como coisa, como em si.

As Sachvorstellungen pretendem dar conta de outra coisa, do conteúdo não referencial das representações inconscientes. Embora haja um sentido em que estas representações de coisa se referem a algo, uma vez que a definição de representação de coisa se apresenta "ao sistema inconsciente como continuidade de representações brutas, seqüela dos investimentos de objetos originários, ocultação dos 'investimentos de objetos' (Objektbesetzungen)” (p.106), tal sentido “designa um ponto irredutível, anterior à verbalização, sede do inconsciente: como memória ou estoque de traços mnêmicos” (p.107), e não nos leva à simples equação em que essas representações sejam de objetos no sentido tradicional de correlato objetivo do sujeito que percebe. Como temos visto, não remete a objetos do 
mundo exterior, mas sim a investimentos de traços mnêmicos. O importante é que estas representações de coisa estão investidas a partir da pulsão com um determinado montante de energia (libido) pelo qual se desprendem da idéia objetiva de referência para entrar no âmbito da condição de ser significativas, uma vez que não são simples objetos apenas percebidos, mas sim carregados de interesse, em função do qual entrarão em relação com outras representações. É nessas relações entre representações que aquilo que se torna consciente adquire significado ou, melhor ainda, tem um sentido. Assim, “o processo psicológico de tornar-se consciente corresponde, então, à revivescência dos concomitantes verbais da representação de coisa" (p.106).

Agora fica evidente por que razão Freud foi seduzido pela idéia kantiana de coisa em si: o real psíquico só nos é acessível por aquilo que se torna consciente. Se Freud está pensando em que o conteúdo do inconsciente é semelhante ao em si, não é porque isto seja o anterior a qualquer percepção, o que está fora do mundo dos fenômenos, mas sim por ser exaustiva e diretamente incognoscível, aquilo que permanece com a qualidade de inconsciente exceto aquilo que vence as barreiras do recalcamento e chega, mesmo que disfarçado, à consciência. Assemelha-se ao 'em si' kantiano em que, igual a este, aquele em si, o real psíquico, é um incognoscível do qual só temos notícias por meio de alguma tradução (fundamentalmente a tradução em palavras), mas de que não podemos dar conta de forma nem direta nem acabada. Dessa maneira, a teoria das representações que está em jogo na analítica está ligada à idéia de realidade psíquica que se instaura com a psicanálise.

Voltando ao nosso esquema comparativo, vemos que Freud reintroduz a distinção representação de palavra/coisa, porém com um sentido bem diferente. Cabe, então, que nos perguntemos em que sentido Freud vê, se é que vê, uma continuidade com a distinção postulada em 1891? Em geral se faz referência à reinstauração desse par na metapsicologia, porém sem indicar que esta já significa outra coisa, e perde o sentido que ele tinha dado em 1891, mais apegado ao associacionismo realista de Mill: o associacionismo realista de Freud, sendo um associacionismo, é muito diferente, visto que aqui coisa e realidade psíquica exercem um papel central, porém com o significado que têm para a psicanálise e a partir da psicanálise, e que a filosofia não admitirá nem de comum acordo nem por extensão.

\section{V}

Dessa maneira vemos como a doutrina das representações que podemos atribuir à psicanálise freudiana se afasta de visão clássica das representações, presente na filosofia e na psicologia associacionista da época. Freud pode pensar um âmbito representacional não referencial à medida que, ao perder a relação de univocidade 
semântica com os objetos do mundo externo, aquilo que é propriamente psíquico adquire seu significado de modo interno ao sistema que se quer interpretar. Isso tem conseqüências para a divisão sujeito-objeto, já que a noção de objeto perde seu status de objetividade, daquilo que é dado independentemente da apercepção, daquilo que se apresenta com certa permanência, uma vez que aquilo que se está indagando é a realidade psíquica, irredutível à realidade física. ${ }^{6}$ Do mesmo modo, a noção de sujeito deixa de ter um caráter de algo cujos limites estão definidos. De fato, em psicanálise não podemos falar, em sentido estrito, de sujeito como se se tratasse de uma unidade evidente; pelo contrário, a psicanálise introduz uma fissura ali onde antes se concebia um sujeito dado, imediato, evidente.

Por sua vez, o campo da significação entra em cheio naquilo que, até agora, era apenas terreno de observação e descrição, com a conseqüência de abrir novos espaços para a reflexão epistemológica que, em grande medida, se verão refletidos na ulterior discussão acerca do status e da metodologia das ciências humanas e naturais. Neste sentido a psicanálise entra no terreno da filosofia ao propor perguntas no campo do significado, da epistemologia, da linguagem, como um saber que revisa e questiona antigos pressupostos e instaura novas formas de inteligibilidade.

Nesta linha de perguntas que o saber psicanalítico abre situamos a problemática representacional. As representações de coisa (o propriamente psíquico, o conteúdo do inconsciente) são representações, porém seu conteúdo não é referencial no sentido de remeter a uma única coisa. A trama de relações representacionais é o próprio conteúdo das representações de coisa. Se uma representação é algo que está no lugar de outra coisa, e por conseguinte é intencional e, ao mesmo tempo tanto as representações de palavra, que não remetem a uma única coisa, nem as representações de coisa a um único traço mnêmico ou objeto indiferente à maneira de objetivo, então o próprio conceito de intencionalidade se torna mais complexo e, com ele, o de significado.

Esta implicação tem seu impacto num dos problemas centrais para a filosofia como é a noção de significado. Como Ricoeur aponta “...é esta nova abertura para o conjunto do falar humano, àquilo que quer dizer o homem desejante, que dá à psicanálise o direito de participar do grande debate sobre a linguagem" (RICOEUR, 1965, p.10). A psicanálise abre, portanto, a porta ao problema da significação remetendo a um sujeito de desejo cujas ações têm um significado muitas vezes fugidio, não literal, que adquire sentido no contexto de quem fala, dos motivos para querer dizer e, ao mesmo tempo, não querer dizer algo.

\footnotetext{
${ }^{6}$ Este tipo de irredutibilidade ainda não diz nada a propósito da discussão da redutibilidade dos processos psíquicos a processos físicos de algum tipo, mesmo quando um debate a respeito devesse considerar o tipo de independência da realidade psíquica a que estamos fazendo alusão aqui.
} 
O diálogo filosofia-psicanálise se atualiza (ou deveria atualizar-se) hoje em dia, quando outras formas de conceber o mental entraram no terreno da filosofia pela porta da ciência naturalizada e tomaram a si mesmas como modelos de explicação dos fenômenos mentais, e desse modo adotam a atitude acrítica de que a psicanálise parece não ter nada a dizer a respeito. No entanto, ao indagar o tipo de pressupostos que a psicanálise questiona e as razões que dá para isso, como propus na presente investigação, abre-se um campo fecundo de problemáticas filosóficas.

Recebido em 16/7/2007. Aprovado em 26/9/2007.

\section{REFERÊNCIAS}

ASSOUN, P. L. (1993) Introducción a la metapsicología freudiana. Buenos Aires: Paidós. XXI.

. (1981) Introducción a la epistemología freudiana. Buenos Aires: Siglo

BERCHERIE. (1983) Génesis de los conceptos freudianos. Buenos Aires: Paidós. FREUD S. (2000) Obras completas. Buenos Aires: Amorrortu.

(1891) "Palabra y cosa", v. XIV, p. 207-213.

(1896) “Carta 52”, v. I, p. 274-280.

(1915) "Lo inconciente”, v.XIV, p.153-201.

IBARRA, A. \& MORMANN T. (2005) Interactive representations. Representaciones, v.1, n.1, p.1-20.

MINHOT, L. (2003) La mirada psicoanalítica. Córdoba: Brujas.

PUTNAM, H. (1988) Realidad y representación. Barcelona: Gedisa.

RICOEUR, P. (1965) Freud: una interpretación de la cultura. México: Siglo XXI. RORTY, R. (1989) La filosofía y el espejo de la naturaleza. Madrid: Cátedra.

TAYLOR, C. (1997) Argumentos filosóficos. Buenos Aires: Paidós. 